\title{
Potential of recombinant inorganic pyrophosphatase antigen as a new vaccine candidate against Baylisascaris schroederi in mice
}

\author{
Yue Xie ${ }^{1 \dagger}$, Sijie Chen ${ }^{2 \dagger}$, Yubo Yan², Zhihe Zhang ${ }^{3}$, Desheng $\mathrm{Li}^{4}$, Hua Yu ${ }^{2}$, Chengdong Wang ${ }^{4}$, Xiang Nong ${ }^{1}$, \\ Xuan Zhou', Xiaobin Gu', Shuxian Wang ${ }^{1}$, Xuerong Peng ${ }^{5}$ and Guangyou Yang ${ }^{1 *}$
}

\begin{abstract}
The intestinal nematode Baylisascaris schroederi is an important cause of death for wild and captive giant pandas. Inorganic pyrophosphatases (PPases) are critical for development and molting in nematode parasites and represent potential targets for vaccination. Here, a new PPase homologue, Bsc-PYP-1, from B. schroederi was identified and characterized, and its potential as a vaccine candidate was evaluated in a mouse challenge model. Sequence alignment of PPases from nematode parasites and other organisms show that BSC-PYP-1 is a nematode-specific member of the family I soluble PPases. Immunohistochemistry revealed strong localization of native Bsc-PYP-1 to the body wall, gut epithelium, ovary and uterus of adult female worms. Additionally, Bsc-PYP-1 homologues were found in roundworms infecting humans (Ascaris lumbricoides), swine (Ascaris suum) and dogs (Toxocara canis). In two vaccine trials, recombinant Bsc-PYP-1 (rBsc-PYP-1) formulated with Freund complete adjuvant induced significantly high antigen-specific immunoglobulin (Ig)G but no IgE or IgM responses. Analysis of IgG-subclass profiles revealed a greater increase of IgG1 than IgG2a. Splenocytes from rBsc-PYP-1/FCA-immunized mice secreted low levels of Thelper (Th)1-type cytokines, interferon- $\gamma$ and interleukin (IL)-2, while producing significantly high levels of IL-10 and significantly elevated levels of IL-4 (Th2 cytokines) after stimulation with rBSC-PYP-1 in vitro. Finally, vaccinated mice had $69.02-71.15 \%$ reductions (in 2 experiments) in larval recovery 7 days post-challenge (dpc) and $80 \%$ survival at $80 \mathrm{dpc}$. These results suggest that Th2-mediated immunity elicited by rBsc-PYP-1 provides protection against B. schroederi, and the findings should contribute to further development of Bsc-PYP-1 as a candidate vaccine against baylisascariasis.
\end{abstract}

\section{Introduction}

Baylisascariasis is a neglected zoonotic helminthic disease caused by parasitic nematodes of the genus Baylisascaris (Nematoda: Ascaridida) with great medical and veterinary significance worldwide [1-3]. The causative pathogens, Baylisascaris spp., are widely distributed in the giant panda (Ailuropoda melanoleuca), red panda (Ailurus fulgens), raccoon (Procyon lotor), Ursid species (Ursus maritimus, Ursus arctos pruinosus, Selenartos thibetanus mupinensis and Ursus arctos lasiotus) and other mammals including humans and can lead to severe clinical visceral (VLM), ocular (OLM) and neural

\footnotetext{
* Correspondence: guangyou1963@aliyun.com

${ }^{\dagger}$ Equal contributors

'Department of Parasitology, College of Veterinary Medicine, Sichuan Agricultural University, Ya'an 625014, China

Full list of author information is available at the end of the article
}

larva (NLM) migrans in these definitive or intermediate hosts [4-7]. Among them, Baylisascaris schroederi is the only endoparasite that appears to be consistently found in the giant panda, a flagship species for wildlife conservation in China, and represents a significant threat to both wild and captive populations [8,9]. In nature, $B$. schroederi infection rates among wild pandas may reach between $50-100 \%$, making it one of the leading causes of death from primary and secondary infection in wild populations $[4,10,11]$. Zhang et al. demonstrated that the probability of death of wild pandas caused by this pathogen increased significantly between 1971 and 2005, and the associated VLM was the most important cause of death during the recent period 2001-2005 [8]. As with all ascarid species, B. schroederi infection follows a trophic pathway by ingestion with life cycle completion 
without intermediate hosts. This parasite (at the adult stage) usually inhabits the intestines of the giant panda, while its migrating larvae may disseminate into various body tissues. B. schroederi can induce extensive inflammation and scarring of the intestinal wall and parenchyma of the liver and lung (mainly caused by larvae), as well as intestinal obstruction, inflammation and even death (caused by adults) in giant pandas [9,12-14]. Until now the control of $B$. schroederi infection in pandas is relied chiefly on chemotherapy, and treatment with antiparasitic drugs requires multiple doses until the animal ceases to expel worms or shed eggs in feces [9]. However, alternative preventative and treatment strategies are needed due to the rapid emergence of multidrug-resistant ascarids and pollution of the food chain and the environment from chemotherapy, as well as the persistent exposure of host animals to parasites of different stages in their surroundings. Vaccines, particularly target antigens that play crucial roles in the survival, development and reproduction of parasitic nematodes would be an ideal control strategy.

Inorganic pyrophosphatases (PPases, EC 3.6.1.1), a class of cytosolic enzymes catalyzing the hydrolysis of inorganic pyrophosphate $\left(\mathrm{PP}_{\mathrm{i}}\right)$ to ortho-phosphate $\left(\mathrm{P}_{\mathrm{i}}\right)$, are widely distributed among living cells and function in energy metabolism, lipid metabolism and some biosynthetic reactions [15]. PPases are essential for the growth and development of prokaryotes, fungus, nematodes and plants (e.g., tobacco and potato) [16-22]. For parasites, such as Ascaris roundworms, PPases are believed to be further involved in molting, as indicated in Ascaris suum by RNAmediated interference and enzyme activity inhibition assays $[23,24]$. Considering the important roles of PPases in life processes of various organisms including parasitic nematodes, some of these enzymes have been selectively targeted for pharmaceutical and vaccine purposes [25]. For example, an adjuvanted recombinant PPase antigen from ascarids was recently demonstrated to induce a high level of protection (>70\%) against A. suum challenge in mice, and its potential for use as a candidate vaccine against ascariasis is further suggested in pigs [23]. However, no information on PPases of $B$. schroederi is available to date. More importantly, B. schroederi-specific protein antigens as potential targets for vaccines and/or chemotherapeutic agents are still scarce with only three antigen molecules (Bs-Ag1, Bs-Ag2 and Bs-Ag3) available $[12,13,26]$, and the precise mechanism of protective immunity against $B$. schroederi infection has not been determined, although preliminary results have been published on other gastrointestinal parasitic infections showing induction of strong $\mathrm{T}$ helper (Th) 2-biased responses in various experimental animal models [27-30].

Therefore, the aims of the present study were (i) to clone and express a new PPase, Bsc-PYP-1, from B. schroederi; (ii) to investigate the localization of this native protein in adult parasites and its expression profiles at various developmental stages of $B$. schroederi, including embryonated eggs, 2nd and 3rd-stage larvae (L2-L3) and adults; (iii) to test the immunogenicity and protective potential of recombinant Bsc-PYP-1 (rBsc-PYP-1) following vaccination with Freund complete adjuvant (FCA) in challenged mice; and finally (iv) to determine the $\mathrm{T}$ helper (Th) 1 and/or Th2 immune profile induced by vaccination with this recombinant protein based on levels of serum immunoglobulin (Ig)G, its subclasses (IgG1 and IgG2a) and cytokines (e.g., interleukin (IL)-2, IL-4, IL-10 and interferon (IFN)- $\gamma$ ). To our knowledge, this is the first report that evaluates the protective efficacy and corresponding immune mechanisms of the $\mathrm{r} B s c$-PYP-1 protein as a vaccine in a mouse challenge model. The results will contribute to improve our understanding of Bsc-PYP-1 as a candidate vaccine against baylisascariasis.

\section{Materials and methods Parasites}

B. schroederi female adults derived from naturally infected giant pandas were provided by the Department of Parasitology, College of Veterinary Medicine, Sichuan Agricultural University (Ya'an, China). Unembryonated and embryonated eggs were obtained essentially as described elsewhere [31]. B. schroederi infective L2 from embryonated eggs and liver-stage L3 from infected mice were collected as previously described [32]. Adult Ascaris lumbricoides worms were obtained from patients after treatment with piperazine in Jianyang, Sichuan Province of China. Adult A. suum and adult Toxocara canis were isolated from infected pigs at a local slaughterhouse in Ya'an and an infected dog in Chengdu, China, respectively. Protein concentrations of phosphate-buffered saline (PBS)-soluble parasite antigens were measured using the microbicinchoninic acid (BCA) protein assay kit (Pierce/ Thermo Fisher Scientific, Asheville, NC, USA).

\section{Animals}

Six- to eight-week-old female specific-pathogen-free (SPF) $\mathrm{BALB} / \mathrm{c}$ mice were purchased from the Laboratory Animal Center of Sichuan University (Chengdu, China). New Zealand white rabbits were obtained from the Laboratory Animal Center of Sichuan Agricultural University. All animals were housed under a barrier environment in sterile cages in the laboratory animal house of the National Institute of Animal Health (NIAH) and were fed pelleted food and sterilized water ad libitum. Animals were acclimated to these conditions for 1 week prior to the experiment. Institutional Ethical and Animal Care guidelines were followed during the sampling exercise, and all procedures were reviewed and approved by the Institute of Animal 
Health Animal Care and Use Committee of Sichuan Agricultural University of China.

\section{Amplification and bioinformatic analysis of Bsc-PYP-1 coding sequence}

Total RNA isolation from female adults of B. schroederi and the first-strand cDNA synthesis were performed according to standard protocols [12]. The resulting cDNA was used as the template for PCR amplification with a sense primer (5'-TAAAGATGGCATTGGCCGCATCG$\left.3^{\prime}\right)$ and an antisense primer (5'-CACTCTTTGATGAAA TGCCATCTGTCA-3') designed to target the A. suum AdR44 cDNA sequence (GenBank accession: AB091401). The PCR amplified product was gel-purified, cloned into the pMD19-T vector (TaKaRa, China) and sequenced. An Open Reading Frame Finder [33] and the Lasergene software package for Windows (DNASTAR, Madison, WI, USA) were used to analyze the open reading frame (ORF) of the nucleotide sequence and deduce the amino acid sequences. Similarity comparisons with previously reported sequences in GenBank were performed using DNAMAN version 3.0 (Lynnon Biosoft, Quebec, Canada) and on-line Blast tools at the National Center for Biotechnology Information (NCBI) website [34]. Based on their similarities, multiple sequence alignment and phylogenetic analysis were obtained. Sequences were aligned with ClustalW2 [35], and the phylogenetic tree was constructed by the neighbor-joining (NJ) method [36] and plotted with MEGA 3.1 [37]. In addition, the molecular weight (MW) and isoelectric point (pI) of Bsc-PYP-1 were calculated using ProtParam [38], and the signal sequence was predicted with the SignalP 3.0 server [39].

\section{Expression and purification of recombinant Bsc-PYP-1 fusion protein}

A partial coding region of Bsc-PYP-1 cDNA, except for the predicted signal peptide, was amplified by PCR using a sense primer (5'-CCCAAGCTTCGACAATCTCGCAGT$\left.3^{\prime}\right)$ containing a HindIII site (italics) and an antisense primer (5' -CCGCTCGAGTCACTCTTTGATGAAATGCCA TCTGTC-3') containing an XhoI site (italics). The PCR products were digested with HindIII and XhoI (TaKaRa), gel-purified and ligated into the plasmid expression vector pET32a (+) (Novagen, Madison, WI, USA). The resulting plasmid with a correct Bsc-PYP-1 insert was transformed into E. coli BL21 (DE3) cells (Invitrogen, Carlsbad, CA, USA) and subsequently grown at $37{ }^{\circ} \mathrm{C}$ to an $\mathrm{OD}_{600}$ of 0.6 in Luria-Bertani (LB) broth supplemented with $50 \mu \mathrm{g} / \mathrm{mL}$ ampicillin. The transformed cells were induced by adding $1 \mathrm{mM}$ isopropyl- $\beta$-D-thiogalactopyranoside (IPTG) for $5 \mathrm{~h}$ at $37^{\circ} \mathrm{C}$. The cells were harvested and resuspended in lysis buffer [50 mM NaH${ }_{2} \mathrm{PO}_{4}$ (pH 8.0), $10 \mathrm{mM}$ Tris- $\mathrm{HCl}$ ( $\mathrm{pH} 8.0), 100 \mathrm{mM} \mathrm{NaCl}$. The samples were then sonicated until they were no longer viscous. Cell lysates and inclusion bodies were pelleted by centrifugation at $25000 \times g$ for $15 \mathrm{~min}$ at $4{ }^{\circ} \mathrm{C}$. The pellets were resuspended in lysis buffer plus $8 \mathrm{M}$ urea and incubated on ice for 1-2 $\mathrm{h}$ to completely solubilize the protein. $\mathrm{His}_{6}$ tagged $\mathrm{rBsc}$-PYP-1 proteins were expressed in an inclusion body form and purified by $\mathrm{Ni}^{2+}$ affinity chromatography using a $10 \mathrm{~mL}$ His-Bind Resin column (Novagen) under denaturing conditions as described in the manufacturer's protocol. Proteins eluted with imidazole were concentrated with Amicon Ultra Centrifugal Filter Devices (Millipore, Billerica, MA) and then dialyzed against $\mathrm{PBS}$, containing decreasing concentrations of urea $(8,6,4,3,2$, and $1 \mathrm{M}$, and PBS only). Thereafter, concentrations of purified proteins were measured with the micro-BCA protein assay reagent (Pierce/Thermo Fisher Scientific), and the potential endotoxin contamination was accessed using the limulus amoebocyte lysate-based gel-clot assay as described elsewhere [40].

\section{Sera}

Rabbit immune serum against $B$. schroederi was obtained as previously described [12]. To obtain mouse polyclonal sera against $\mathrm{r} B s c$-PYP-1, 10 female BALB/c mice were immunized with a subcutaneous injection of $50 \mu \mathrm{g}$ of rBsc-PYP-1 purified as described above and mixed with FCA (Sigma, St. Louis, USA), followed by 2 booster immunizations ( 2 weeks apart) using the same route and dose in the same adjuvant. Mice were bled 2 weeks after the second booster immunization. The antisera from the mice were mixed and stored at $-20{ }^{\circ} \mathrm{C}$ until use.

\section{Immunoblot and immunohistochemical analyses}

For immunoblot analysis, parasite antigens or $\mathrm{r} B s c$-PYP1 proteins were lysed in an electrophoresis sample buffer, run on 10\% SDS-PAGE, transferred onto nitrocellulose membranes and blocked with 5\% skim milk in Tris-buffered saline (TBS) buffer for $1 \mathrm{~h}$. Parasitederived Bsc-PYP-1 was detected by incubation of the membranes with the mouse anti-rBsc-PYP-1 serum. To determine the antigenicity of $\mathrm{r} B s c$-PYP-1, rabbit or mouse sera from animals repeatedly inoculated with $B$. schroederi embryonated infective eggs, anti-rBsc-PYP-1 mice serum and naïve rabbit or mouse sera were used. After three washes with TBS-Tween 20 (TBST), the membranes were further incubated for $2 \mathrm{~h}$ with 1:200 diluted alkaline phosphatase-conjugated goat anti-mouse or anti-rabbit IgG (ICN Pharmaceuticals, Costa Mesa, CA). Protein signals were visualized using nitroblue tetrazolium and 5-bromo-4-chloro-3-in-dolylphosphate (NBT/BCIP; USB, Cleveland, OH). For immunohistochemical analysis, adult female $B$. schroederi sections were probed with specific anti-rBsc-PYP-1 mouse serum (1:100), followed by a peroxidase-labeled anti-mouse IgG goat antibody (Biosynthesis Biotechnology Co., Ltd., Beijing, 
China) [19]. Slides were mounted and examined under a light microscope (Nikon Optiphot II, Nikon, Japan).

\section{Immunization and challenge}

For immunization, rBsc-PYP-1 proteins were suspended in PBS (0.01 M, pH 7.4) at a concentration of $600 \mu \mathrm{g} / \mathrm{mL}$ and mixed with an equal volume of FCA (Sigma) as described previously [13]. Control FCA mixed with PBS and control PBS were also used for challenge studies. In the first trial, 90 mice were randomly assigned into three groups (30 animals per group) and injected subcutaneously with the $\mathrm{rBsc}$-PYP-1 suspension, FCA mixed with PBS or PBS alone (100 $\mu \mathrm{L}$ per animal). First and second booster injections were prepared in the same manner and administered at the same dose at 14-day intervals. Two weeks after the final injection, 10 mice from each group were sacrificed, and the spleens were removed aseptically for cytokine assays. The remaining 20 animals in each group were inoculated orally with 3200 B. schroederi infective embryonated eggs. Ten out of twenty mice challenged with $B$. schroederi from each group were sacrificed and dissected at one week post-challenge (wpc). After histopathological examination, lungs and livers were removed from the animals and minced with a surgical knife, and larvae were recovered by the Baermann method as described by Slotved et al. [41] and counted under a light microscope (Nikon). For the last 10 remaining mice in each group, mortality was monitored over a period of 80 days after the challenge, and relative percent of survival (RPS) was calculated as follows: RPS $=\{1-(\%$ mortality in immunized mice / \% mortality in control mice) $\} \times 100$, as described elsewhere [42].

In order to further assess the potential efficacy of $\mathrm{rBsc}$ PYP-1 as a new vaccine candidate against B. schroederi, the vaccination trial with mice was repeated in trial II essentially as described in trial I, with the exception that the challenge occurred 1 week after the final booster immunization. The overall experimental design is summarized in Table 1. Serum samples in both trials were collected from the tail vein after each immunization and at $42,49,63,77,84$ and 91 days post-vaccination (dpv) for antibody assays and for analysis of the kinetics of humoral immune response throughout the challenge as previously described $[12,13,26,43]$.

\section{Antibody assays}

Measurements of Bsc-PYP-1-specific serum IgM, IgE, IgG, and IgG-subclass (e.g., IgG1 and IgG2a) antibodies in immunized mice derived from trials I and II were performed using enzyme-linked immunosorbent assays (ELISA). The IgM, IgG and IgG subclass antibody levels were determined with horseradish peroxidase (HRP)conjugated goat anti-mouse IgM, IgG and IgG subclass antibodies (Bethyl Laboratories, Montgomery, TX, USA).
Affinity purified goat anti-mouse IgM, IgG, IgG1 and IgG2a (Bethyl Laboratories) were used as standards. For rBsc-PYP-1-specific IgE measurements, anti-mouse IgE was used as the capture antibody, and IgE was quantified by using biotinylated anti-mouse IgE (Bethyl Laboratories) coupled with the standard produced from rat monoclonal anti-mouse IgE antibody (diluted 1:10 000) (American Research Products, Belmont, MS, USA) as described elsewhere $[23,44]$.

ELISA were performed in polystyrene 96-well microtiter plates (Invitrogen) using $100 \mu \mathrm{L}$ reaction mixtures with $\mathrm{rBsc}$-PYP-1 antigen coated at a concentration of $2 \mu \mathrm{g} / \mathrm{mL}$ in $0.1 \mathrm{M}$ carbonate buffer $(\mathrm{pH} 9.6)$ as described previously [13]. The plates were washed after incubation of the plates at $4{ }^{\circ} \mathrm{C}$ for $14-16 \mathrm{~h}$ (and after each subsequent incubation) three times with PBS containing 0.05\% Tween 20 (PBS-T). Wells were blocked with $100 \mu \mathrm{L}$ of PBS-2\% bovine serum albumin (BSA) (Sigma) for $2 \mathrm{~h}$ at $37{ }^{\circ} \mathrm{C}$, and then incubated with serial two-fold dilutions $(100 \mu \mathrm{L})$ of test serum samples at $37{ }^{\circ} \mathrm{C}$ for $1 \mathrm{~h}$. HRPconjugated goat anti-mouse IgM (diluted 1:5000), IgG (diluted 1:500) or IgG subclass (diluted 1:5000) antibodies and HRP-conjugated goat anti-rat IgG (diluted 1:1000) (Bethyl Laboratories) antibody were added to the wells in $100 \mu \mathrm{L}$ for a further incubation at $37^{\circ} \mathrm{C}$ for $1 \mathrm{~h}$. Both test sera and conjugates were diluted in PBS. Antibody binding was detected at $37{ }^{\circ} \mathrm{C}$ with $100 \mu \mathrm{L}$ of o-phenylenediamine dihydrochloride (OPD; Sigma) substrate $(0.4 \mathrm{mg} / \mathrm{mL}$ OPD, $50 \mathrm{mM}$ dibasic sodium phosphate, $25 \mathrm{mM}$ citric acid and $30 \% \mathrm{H}_{2} \mathrm{O}_{2}$ ), and the color reaction was terminated with $100 \mu \mathrm{L}$ of $2 \mathrm{M}$ $\mathrm{H}_{2} \mathrm{SO}_{4}$. The results were obtained with a microplate reader (Dynatech MR500, Deckendorf, Germany), and the endpoint titer was defined as the highest dilution of serum at which the optical density at $490 \mathrm{~nm}\left(\mathrm{OD}_{490}\right)$ was at least above the doubled blank control $\left(\mathrm{OD}_{490}\right.$ 0.15). Negative and blank controls were included on each plate. Antibody concentrations were calculated using a standard curve generated with reference sera (Bethyl Laboratories).

\section{Spleen cell culture and cytokine assays}

Spleen cell suspensions were prepared essentially as described previously $[23,45]$. After isolation, splenic cells $\left(4 \times 10^{6}\right)$ were subsequently cultured at $37^{\circ} \mathrm{C}$ and $5 \% \mathrm{CO}_{2}$ in 24-well plates in a final volume of $1.0 \mathrm{~mL} /$ well. The cells were stimulated with rBsc-PYP-1 antigen $(15 \mu \mathrm{g} / \mathrm{mL})$ for $72 \mathrm{~h}$, and culture supernatants were collected and stored at $-80{ }^{\circ} \mathrm{C}$ for subsequent cytokine analysis using a commercially available mouse Ad Litteram ELISA Kit with pre-coated plates (ADL, San Diego, CA, USA) for IL-2, IL-4, IL-10 and IFN- $\gamma$. Cytokine concentrations were calculated against standard curves constructed with supernatants containing known amounts 
Table 1 Experimental design of mouse vaccination and challenge

\begin{tabular}{|c|c|c|c|c|c|c|}
\hline \multirow{2}{*}{$\begin{array}{l}\text { Trial and } \\
\text { experimental group }\end{array}$} & \multirow[b]{2}{*}{ Number of mice } & \multirow{2}{*}{$\begin{array}{l}0,2,4 \text { wpv }^{b} \\
\text { Vaccination } \\
\text { (3 times per group) }\end{array}$} & \multicolumn{2}{|l|}{ 6-wpv ${ }^{b}$} & \multirow{2}{*}{$\begin{array}{l}\text { 1-wpc }{ }^{c} \\
\text { Larval recovery } \\
\left(\text { No. }^{\text {a) }}\right) \\
\end{array}$} & \multirow{2}{*}{$\begin{array}{l}\text { 1-11 wpc }{ }^{c}(80-\text { dpc }) \\
\text { Mortality } \\
\left(\text { No. }^{\mathrm{a}}\right) \\
\end{array}$} \\
\hline & & & $\begin{array}{l}\text { Cytokine assay } \\
\text { (No. }{ }^{\text {a }} \text { ) }\end{array}$ & $\begin{array}{l}\text { Challenge } \\
\left(\text { No. }^{\text {a, d }}\right)\end{array}$ & & \\
\hline rBsc-PYP-1/FCA/PBS & 30 & rBsc-PYP-1 (FCA plus PBS) & 10 & 20 & 10 & 10 \\
\hline FCA/PBS & 30 & FCA plus PBS & 10 & 20 & 10 & 10 \\
\hline PBS & 30 & PBS & 10 & 20 & 10 & 10 \\
\hline \multirow{2}{*}{$\begin{array}{l}\text { Trial and } \\
\text { experimental group }\end{array}$} & & $0,2,4 \mathrm{wpv}^{\mathrm{b}}$ & 5-wpv ${ }^{b}$ & 6-wpv ${ }^{b}$ & $1-w p c^{c}$ & 1-12 wpc ${ }^{c}$ (80-dpc) \\
\hline & Number of mice & $\begin{array}{l}\text { Vaccination } \\
\text { ( } 3 \text { times per group) }\end{array}$ & $\begin{array}{l}\text { Challenge } \\
\left(\text { No. }^{\mathrm{a}}\right)\end{array}$ & $\begin{array}{l}\text { Cytokine assay } \\
\left(\text { No. }^{a}{ }^{e}\right)\end{array}$ & $\begin{array}{l}\text { Larval recovery } \\
\text { (No. }{ }^{a, f} \text { ) }\end{array}$ & $\begin{array}{l}\text { Mortality } \\
\text { (No. }{ }^{a} \text { ) }\end{array}$ \\
\hline rBsc-PYP-1/FCA/PBS & 30 & rBsc-PYP-1 (FCA plus PBS) & 20 & 10 & 10 & - \\
\hline FCA/PBS & 30 & FCA plus PBS & 20 & 10 & 10 & - \\
\hline PBS & 30 & PBS & 20 & 10 & 10 & - \\
\hline
\end{tabular}


of mouse recombinant IL-2, IL-4, IL-10 and IFN- $\gamma$. All standards and samples were run in triplicate.

\section{Statistical analysis}

The data were expressed as the means \pm standard deviations (SD). Comparisons between experimental groups were performed by one-way ANOVA, LSD, Duncan's test or Scheffe's test using SPSS13.0 Data Editor (SPSS Inc., Chicago, IL, USA). $P$ values $<0.05$ were considered to be significant. All experiments were carried out a minimum of two times with 10 mice per group. Percent reduction was calculated as follows: \% reduction $=[$ (average number of larvae recovered from control mice - average number of larvae recovered from immunized mice)/average number of larvae recovered from control mice] $\times 100$, as previously described [12]. In addition, the nucleotide sequence determined in the present study has been deposited in the DDBJ/EMBL/GenBank database under accession number GQ859591.

\section{Results}

Molecular cloning and identification of Bsc-PYP-1

The cDNA encoding Bsc-PYP-1 with a length of 1,088 bp was obtained by PCR amplification using specific oligonucleotides designed based on the A. suum DNA sequence (GenBank ID: AB091401.1). Sequence analysis shows that the cloned cDNA contained a single ORF of $1,083 \mathrm{bp}$ coding for a putative protein of 360 amino acids with a predicted molecular mass of $40.507 \mathrm{kDa}$ and pI of 6.32 . The first 20 amino acids corresponded to a signal peptide (Figure 1A). Removal of the signal peptide would result in a mature protein with a molecular mass of $38.478 \mathrm{kDa}$ and a pI of 6.31. Six different clones were sequenced, and no differences were found at the amino acid level.

A homology search for the protein performed using information obtained from NCBI revealed that BscPYP-1 shared the highest amino acid sequence similarity with a PPase protein (AdR44) from A. suum (95.8\%) (GenBank accession: BAC66617), followed by $64.4 \%$ similarity with Cre-PYP-1 protein from Caenorhabditis remanei (GenBank accession: EFP04160), and 45.8$56.5 \%$ similarity with putative PPases from parasitic nematodes (Brugia malayi (GenBank accession: EDP36300), Loa loa (GenBank accession: EFO25093) and Trichinella spiralis (GenBank accession: EFV52164)) and free-living nematodes (Caenorhabditis elegans (GenBank accession: NP_001023073) and Caenorhabditis briggsae (GenBank accession: XP_002633752)) (Figure 1A). Sequence similarities were found throughout the protein but less frequently at both ends. Moreover, a PPase signature sequence (DNDPID) and 13 functionally important and evolutionarily well-conserved active site residues (E:125, K:133, E:135, R:155, Y:170, D:192, D:194, D:197, D:224, $\mathrm{D}: 229, \mathrm{~K}: 231, \mathrm{Y}: 269$ and K:270; in Bsc-PYP-1) in family I soluble PPases were also observed in the sequence analysis

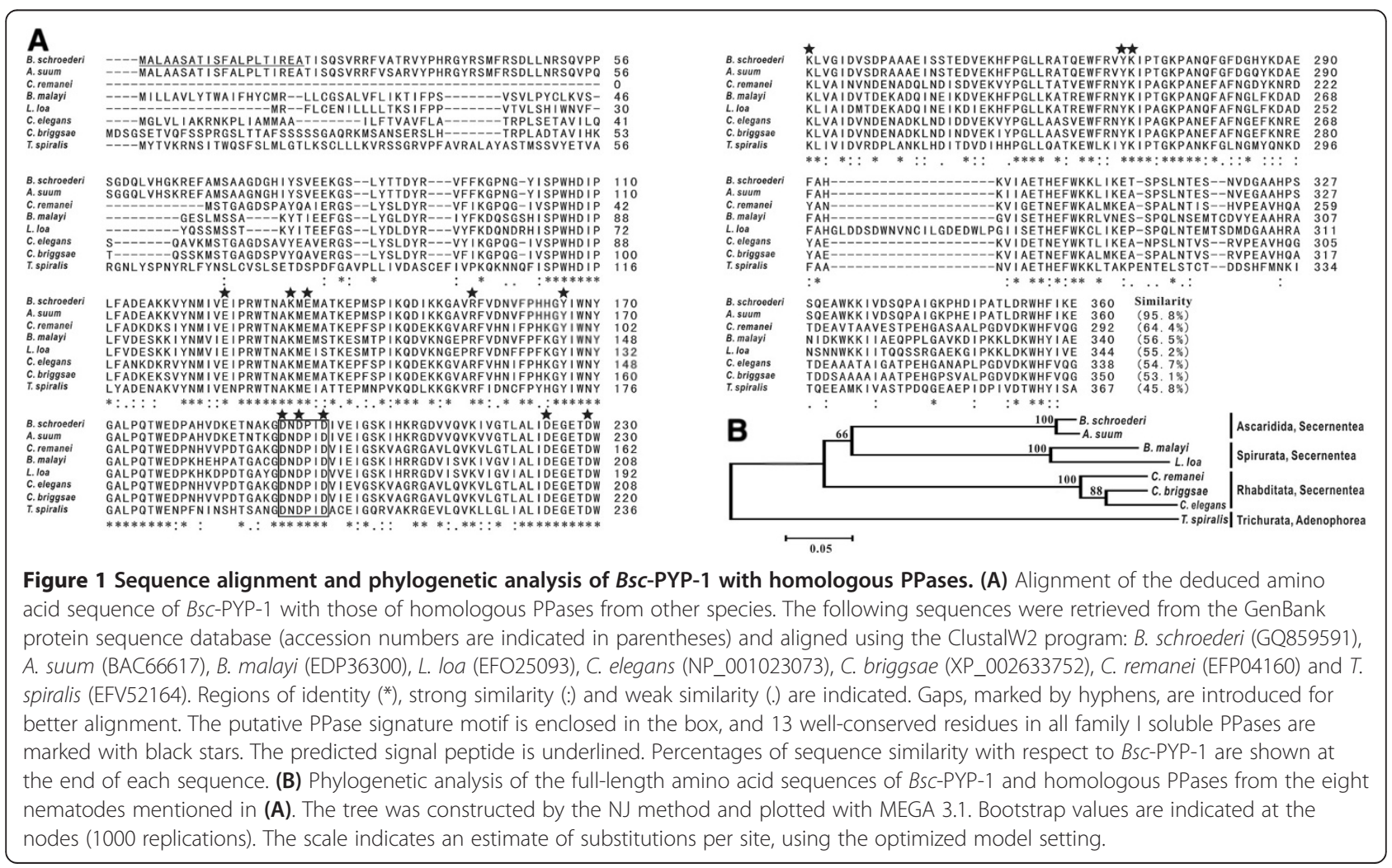


(Figure 1A). Therefore, based on its similarity and conservation of functionally relevant residues with these other protein members of the PPase superfamily, Bsc-PYP-1 was determined to be a family I soluble PPase.

Relationships of the eight nematodes mentioned above, based on the full-length amino acid sequence alignment of the corresponding PPase proteins, were further determined by phylogenic analysis (NJ tree) (Figure $1 \mathrm{~B}$ ). The results were in good agreement with traditional taxonomy, with $B$. schroederi and $A$. suum clustering into a group within the order Ascaridida, B. malayi and L. loa clustering into another group within the order Spirurata, and $C$. remanei, C. elegans and C. briggsae grouping into a branch belonging to the order Rhabditata (Figure 1B).

\section{Expression, purification and biochemical analysis of rBsc-PYP-1}

The cDNA fragment encoding mature Bsc-PYP-1 was successfully sub-cloned into the pET32a (+) prokaryotic expression vector (Invitrogen), and the recombinant protein was overexpressed in E. coli BL21 (DE3) Star cells as a single $\mathrm{His}_{6}$-tagged fusion protein with an expected size of $\sim 58 \mathrm{kDa}$ (data not shown). Since the epitope tag fusion peptide in $\mathrm{rBsc}$-PYP-1 was $\sim 20 \mathrm{kDa}$ in size, $\mathrm{rBsc}$-PYP-1 therefore had an approximate molecular mass of $38 \mathrm{kDa}$, similar to that predicted from the amino acid sequence of Bsc-PYP-1. After induction for $5 \mathrm{~h}$ with IPTG, the transformed bacterial cells expressing peak amounts of $\mathrm{r}$ Bsc-PYP-1 were sonicated. $\mathrm{rBsc}$-PYP-1 found mostly in inclusion bodies were made soluble by extraction with $8 \mathrm{M}$ urea (not shown). After purification by affinity chromatography using His binding columns under denaturing conditions, the rBsc-PYP-1 proteins were subsequently refolded by dialysis against PBS containing successively decreasing concentrations of urea. The yield of $\mathrm{rBsc}$-PYP-1 was approximately $4 \mathrm{mg} / \mathrm{L}$ of bacterial culture. The purity of the preparation was accessed by SDS-PAGE (Figure 2, lane 1) and further characterized by Western blotting using rabbit immune serum against B. schroederi (experimental group), anti-rBsc-PYP-1 mouse serum (positive control), or naïve rabbit and mouse sera (negative controls). A positive band of $58 \mathrm{kDa}$ was observed in the experimental group and positive control, in contrast with the two negative controls, suggesting that $\mathrm{rBsc}$-PYP-1 had good antigenicity (Figure 2, lanes $2-5$ ). The purified $r B s c$-PYP-1 protein was then used for the production of polyclonal antibodies in mice, immunohistochemical analysis and the examination of immunoreactivity with various immune sera, as well as for vaccine experiments using the $B$. schroederi infection mouse model.

\section{Identification of the native Bsc-PYP-1 antigen in B.} schroederi and homologues in other ascarids The native Bsc-PYP-1 antigen was identified at various stages of development in B. schroederi. Expression of

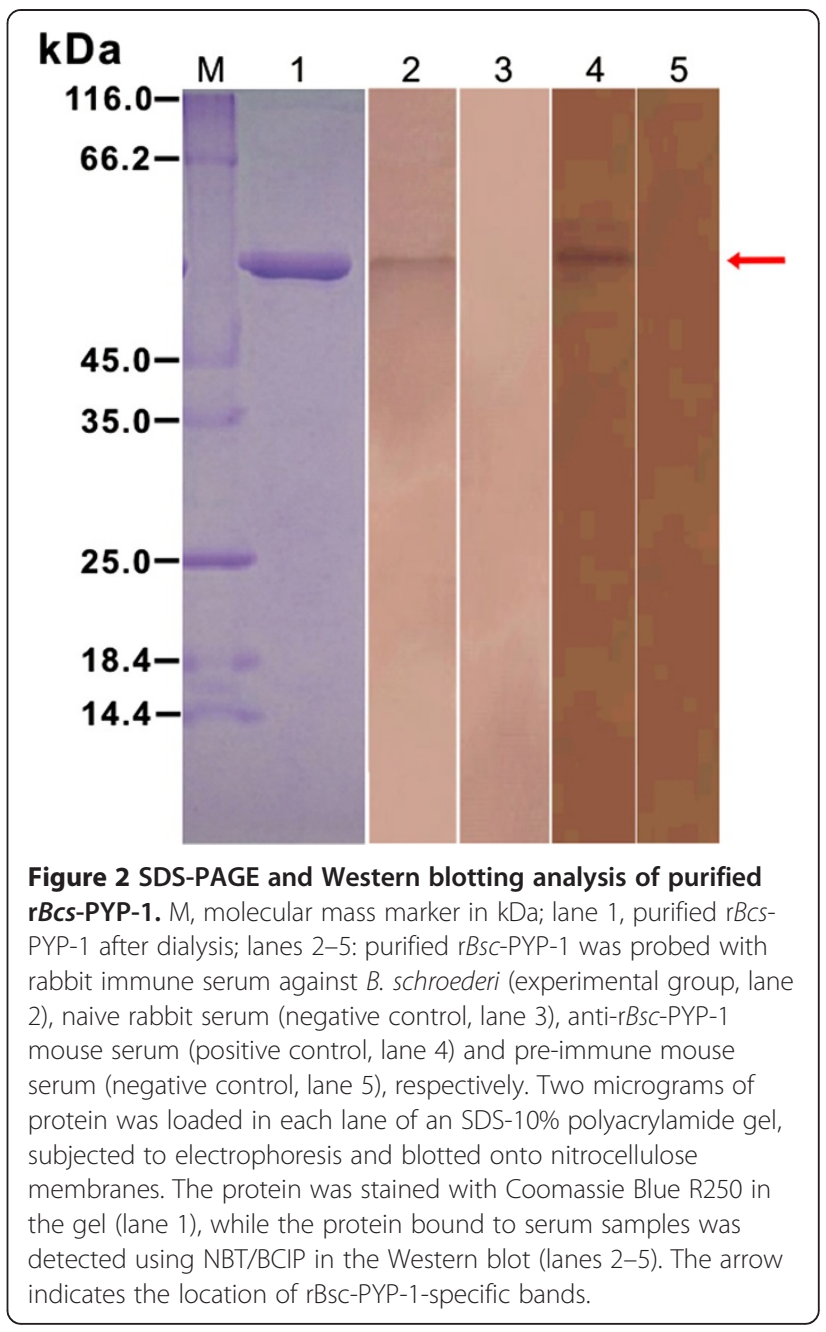

Bsc-PYP-1 from parasites was evaluated by immunoblot analysis using extracts prepared from embryonated eggs, L2, liver-stage L3 and female adult worms. Anti-rBscPYP-1 mouse serum reacted strongly with a $38-\mathrm{kDa}$ parasite-derived antigen from extracts of all B. schroederi life-cycle stages (Figure 3A). By contrast, sera from preimmune mice did not react with any antigens in the parasite extract (not shown). These findings revealed that the endogenous Bsc-PYP-1 protein was commonly expressed in B. schroederi at all developmental stages. Additionally, we also performed immunoblot analysis of human (A. lumbricoides), swine (A. suum) and dog (T. canis) roundworms using anti-rBsc-PYP-1 mouse serum. The mouse serum immunoreacted with a $38-\mathrm{kDa}$ PBS-soluble protein from $A$. lumbricoides, the same size as that of parasite-derived Bsc-PYP-1. Interestingly, $38-\mathrm{kDa}$ immunoreactive bands were also observed in PBS-soluble extracts from $A$. suum and T. canis with nearly equal intensities as parasite-derived Bsc-PYP-1 observed in A. lumbricoides, indicating the presence of a 


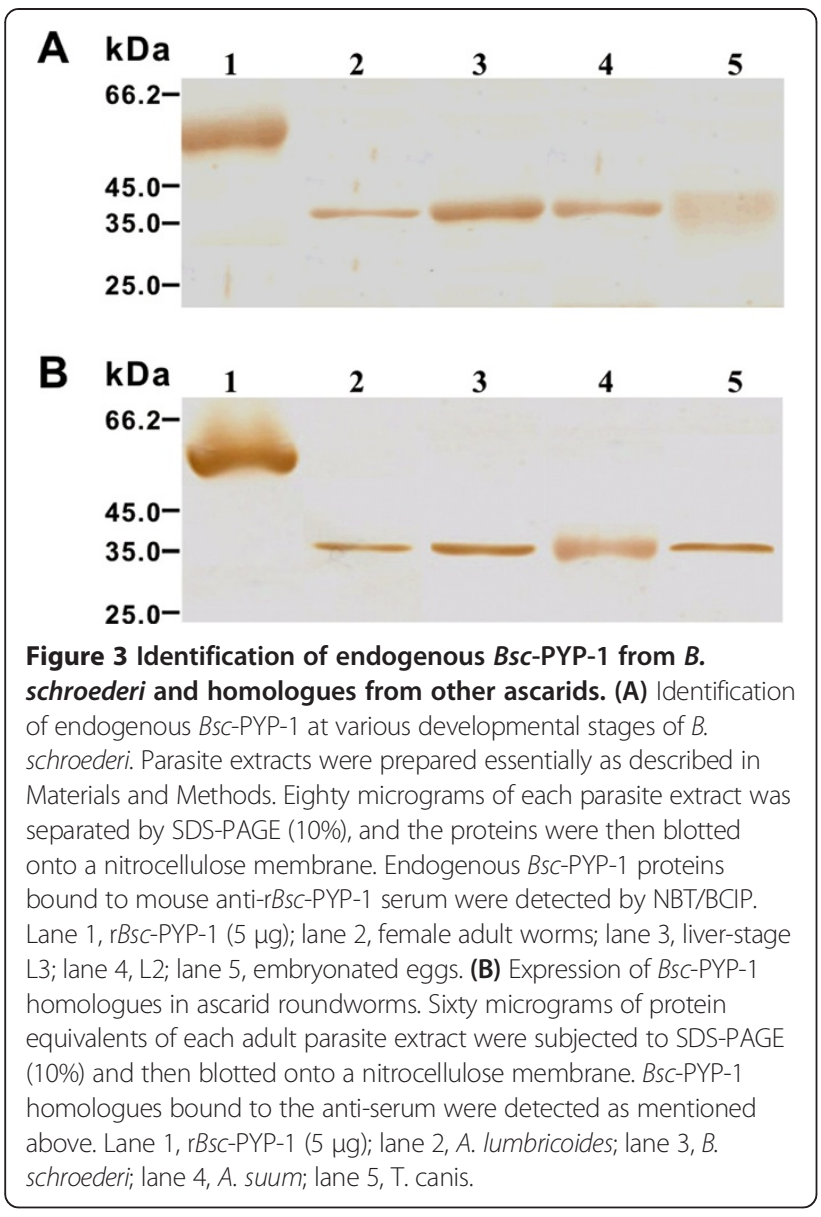

Bsc-PYP-1 homologue in each of these three roundworms (Figure 3B). Sera from mice prior to immunization did not react with any of the antigens present in the parasite extracts (data not shown).

\section{Immunohistochemical localization of endogenous Bsc- PYP-1 in adult female $B$. schroederi worms}

The localization of endogenous Bsc-PYP-1 protein was determined by immunohistochemistry using anti-rBscPYP-1 mouse serum and naïve mouse serum. Specific staining was clearly observed in sections probed with Bsc-PYP-1-specific serum but not in those probed with normal mouse serum (Figures 4A-D). The results show that endogenous Bsc-PYP-1 proteins were localized in various tissues, such as the hypodermis, dorsal and lateral hypodermal chord, muscle tissues, gut epithelium, non-embryonated eggs within the uterus, uterus and ovary of a female adult B. schroderi (Figures $4 \mathrm{~A}$ and $4 \mathrm{C}$ ). Moreover, the ubiquitous presence of Bsc-PYP-1 homologous proteins in various organs of ascarids from humans and swine was also detected (data not shown), consistent with observations from previous studies [19].

\section{Reactivity of rBsc-PYP-1 with various immune sera}

The immunoreactivity of $\mathrm{r} B s c$-PYP-1 with sera from rabbits and mice repeatedly inoculated with $B$. schroderi infective embryonated eggs was examined by immunoblot analysis. Both sera reacted with the rBsc-PYP-1 band with equal intensities, further demonstrating the good antigenicity and immunogenicity of the recombinant protein (Figure 2 and data not shown). Meanwhile, rabbit and mouse pre-immune sera did not react with $\mathrm{rBsc}$-PYP-1.

\section{Immunoprotective effect of $r$ Bsc-PYP-1 as a recombinant protein vaccine against $B$. schroederi}

Efficacy of the $\mathrm{rBsc}$-PYP-1 protein vaccine against $B$. schreoderi migratory-phase infection was investigated in $\mathrm{BALB} / \mathrm{c}$ mice receiving one primary vaccination and two boosters, followed by an oral challenge with $3200 \mathrm{~B}$. schreoderi infective embryonated eggs, based on two independent trials (trials I and II) performed under the same conditions, with the exception of different challenge timepoints, as summarized in Table 1. In trial I, at one wpc, mice vaccinated with $\mathrm{rBs}$-PYP-1/FCA had a significantly $(P=0.024)$ reduced number of $B$. schreoderi liverstage L3 recovered from the liver and a further significant $(P=0.0085)$ reduction in recovered larvae from lungs compared with either mice vaccinated with PBS plus FCA or PBS alone, giving a total reduction of $69.02 \%$ in the number of recovered larvae from immunized mice compared with the controls $(P<0.001)$ (Figure 5$)$. No significant differences were observed between the two control groups. In trial II, a significant larvae reduction (including in the livers and lungs) was also shown in the group vaccinated with $\mathrm{rBsc}$-PYP-1/FCA $(71.15 \%, P<0.001)$ (Figure 5). The reduction of parasitic load in trial II was $2.13 \%$ greater than that in trial I, but this difference was not statistically significant $(P>0.05)$. Moreover, in both trials, histopathological observations of livers and lungs removed from vaccinated mice or non-vaccinated mice show that the occurrence of typical verminous interstitial hepatitis ("milk spotted liver") or verminous pneumonia (pulmonary hemorrhage) following challenge infections was notably reduced in the vaccinated group, compared with the control groups (data not shown).

To further test whether immunization with $\mathrm{rBsc}$-PYP1 could also arrest larval development and decrease the risk of death caused by visceral larval migrans, the 10 remaining mice in each group in trial I were monitored for survival. No mortality was observed among all experimental groups until 8 wpc. Thereafter, the cumulative mortalities of the mice vaccinated with adjuvanted rBsc-PYP-1, PBS plus adjuvant and PBS alone were 20\%, $100 \%$ and $100 \%$, respectively, which corresponded to a relative percent of survival of $80 \%$ for $\mathrm{rBsc}$-PYP-1-vaccinated mice compared with the controls (Figure 6). At 80 days after challenge, all surviving mice were sacrificed. B. schreoderi 


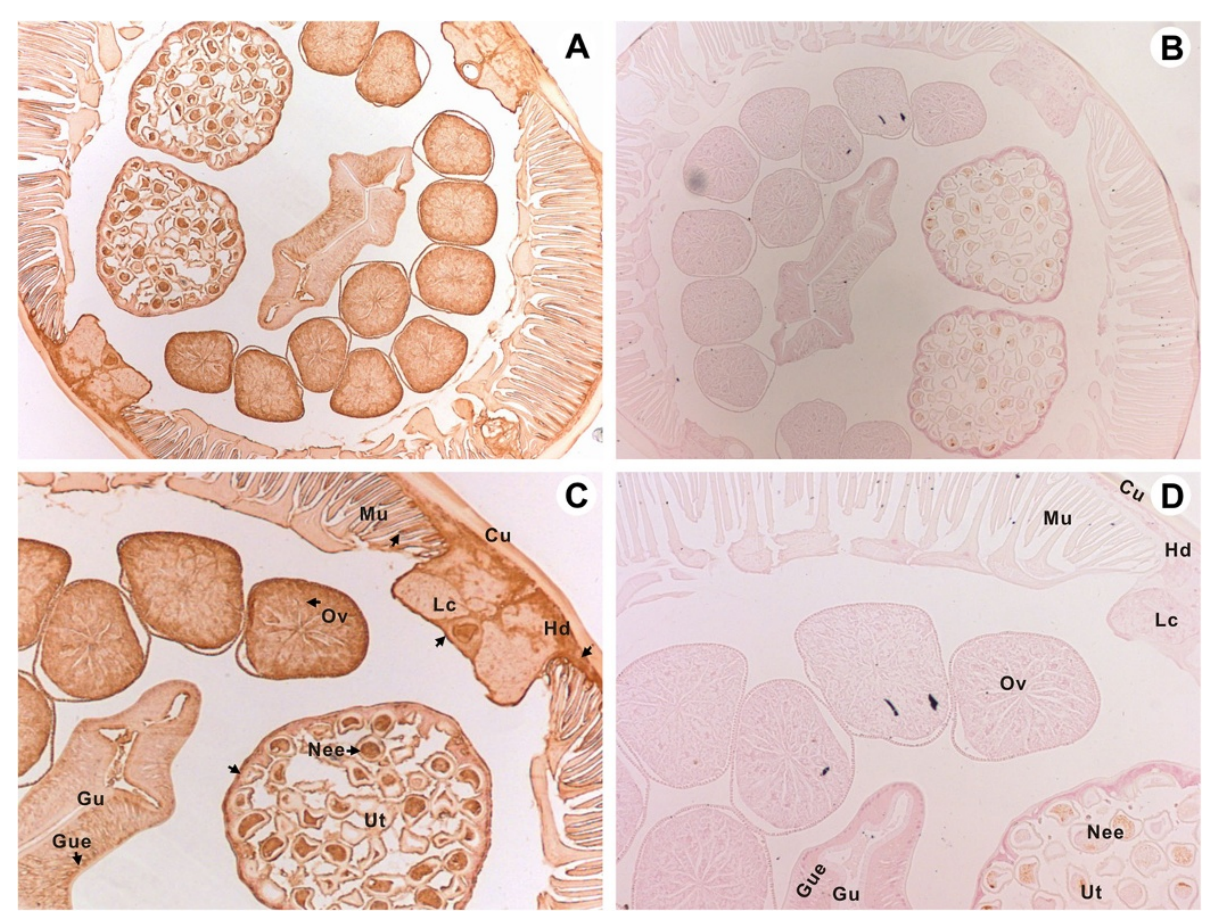

Figure 4 Immunohistochemical localization of endogenous Bsc-PYP-1 in B. schroederi female adult worms. Worms were fixed in paraformaldehyde and embedded in paraffin as described in Materials and Methods. The sections (6- $\mu \mathrm{m}$ thickness) were incubated with either mouse anti-rBsC-PYP-1 serum at 1:100 (A) or pre-immune serum at 1:100 (B) diluted in PBS. (C) and (D) (both 20X) are magnified areas of (A) and (B) (both 10X), respectively. Arrows indicate antibody-labeled regions. Abbreviations: Mu, muscle; Cu, cuticle; Lc, lateral chord; Hd, hypodermis; Ov, ovary; Gu, gut; Gue, gut epithelium; Ut, uterus; Nee, non-embryonated eggs.

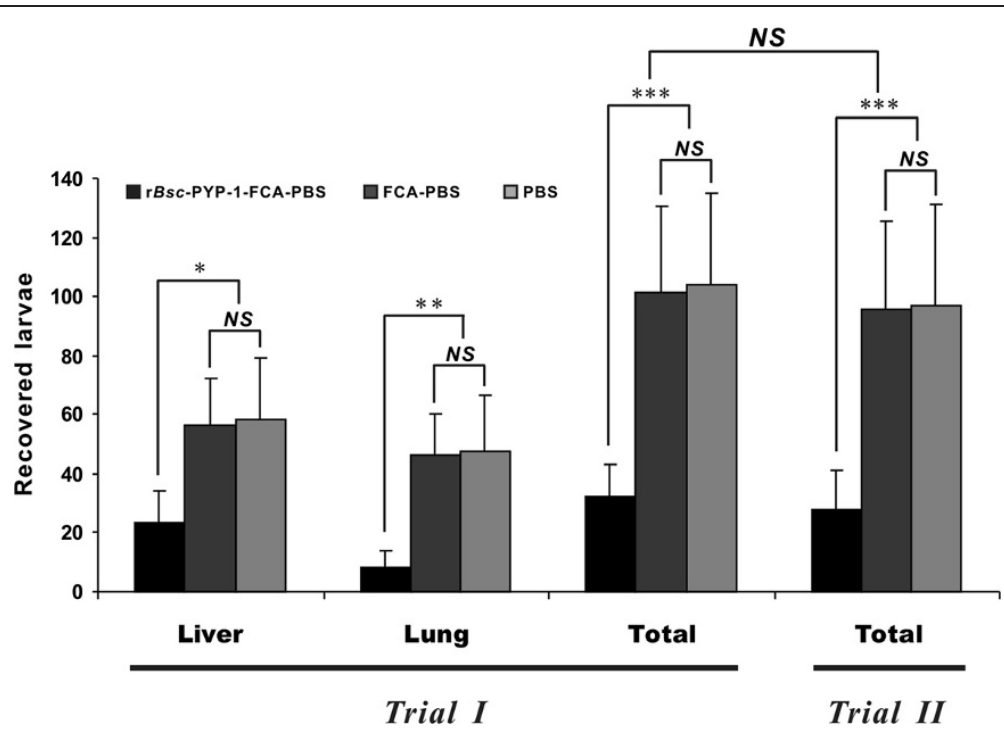

Figure 5 Numbers of $B$. schroederi larvae recovered from livers, lungs or both in mice vaccinated with rBsc-PYP-1 coupled with FCA. Mice were vaccinated three times subcutaneously and then inoculated orally with 3200 B. schroederi infective embryonated eggs at 1 week (trial II) or 2 weeks (trial I) after the final vaccination, as described in Materials and Methods. Mice were sacrificed at $1 \mathrm{wpc}$, and the migrating larvae were recovered from livers or lungs. The results are expressed as the mean \pm SD in each group of 10 mice. Asterisks indicate that the mean value was significantly lower than that of the group vaccinated with PBS plus FCA or PBS alone $\left({ }^{*} P<0.05,{ }^{* *} P<0.01,{ }^{* *} P<0.001\right)$. NS denotes no statistically significant difference, and the error bars indicate SD. 


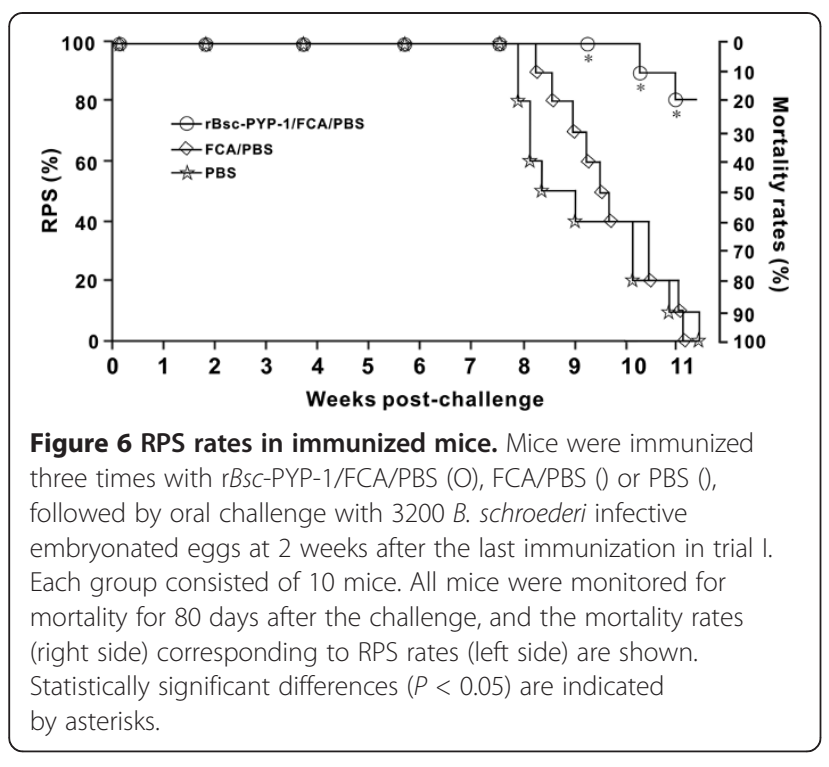

was the only parasitic nematode recovered from the liver, lung, kidney, brain, spleen and muscle tissues of moribund and sacrificed mice during this period, suggesting that mortality was caused by B. schreoderi infection.

Serum antibody responses to vaccination in trials I and II To evaluate the potential of $\mathrm{r} B s c$-PYP-1 to induce hostprotective antibodies, levels of $\mathrm{r} B s c$-PYP-1-specific total IgG, IgE, IgM and IgG-subclasses (including IgG1 and IgG2a) antibodies in vaccinated mice sera derived from trials I and II were measured at various times $(0,2,4,6$, $7,9,11,12,13 \mathrm{wpv})$. As shown in Figure 7A, the amount of $\mathrm{rBsc}$-PYP-1-specific IgG in mice vaccinated with $\mathrm{r} B s c$ PYP-1/FCA within trial I significantly $(P<0.001)$ increased after the first immunization and remained at a high level until the end of the study period, i.e. 91 days, compared with either the adjuvant control or blank control. Interestingly, two peaks of $\mathrm{rBsc}$-PYP-1-specific IgG

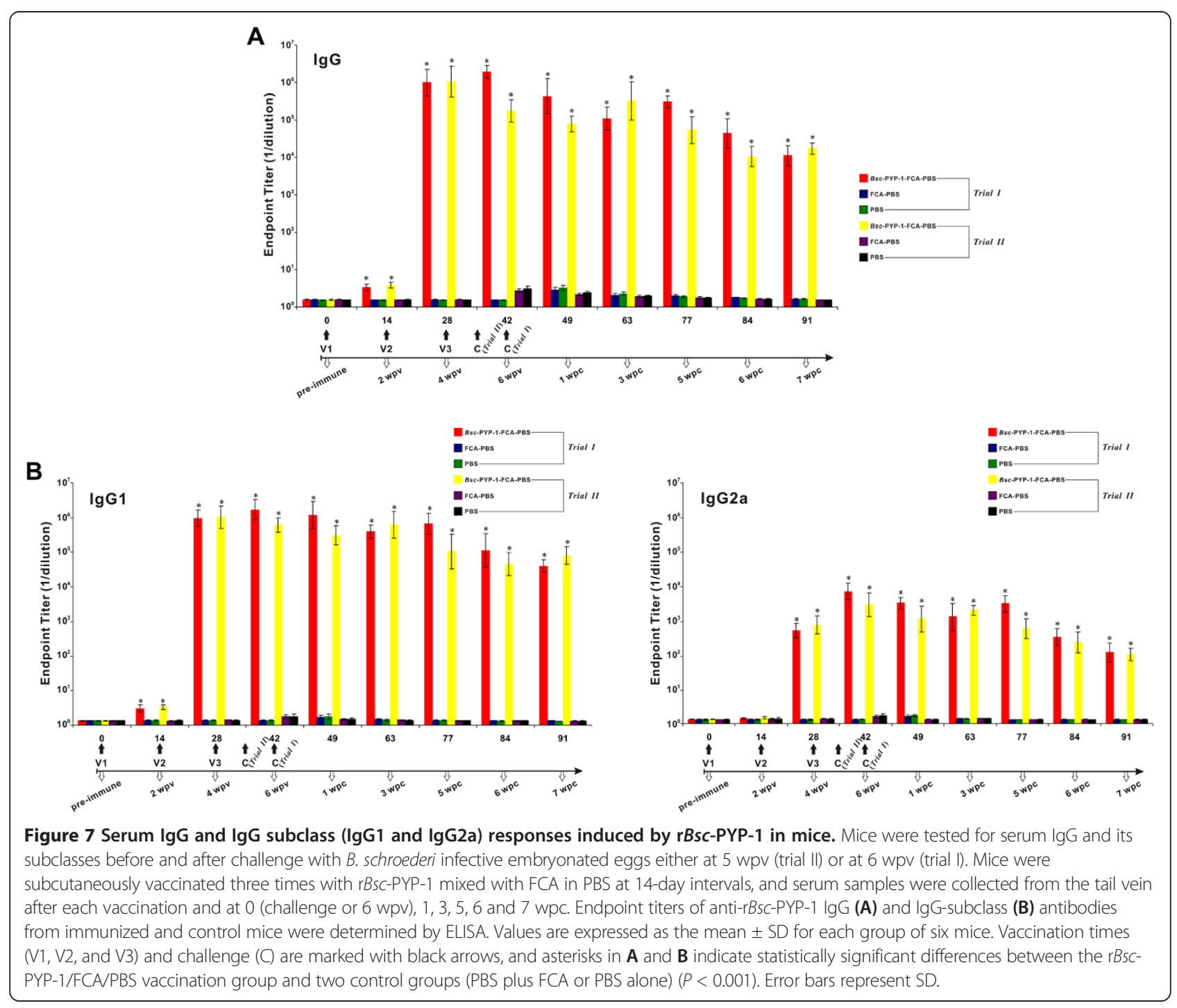


appeared during this course, with one occurring at 6 wpv and another at 5 wpc (Figure 7A). No detectable antigen-specific IgE response was observed in these mice sera even after the first and second booster vaccinations (data not shown). A similar pattern of antibody induction was also seen for $\mathrm{r} B s c$-PYP-1-specific IgM, although the amount increased only slightly at $1 \mathrm{wpc}$ and lasted 2 weeks at a low level. Interestingly, no significant difference in the rBsc-PYP-1-specific IgM level was found compared with the controls (not shown). To further evaluate the type of immune response (Th1 or Th2) induced by $r$ Bsc-PYP-1 in vivo, IgG subclasses were also measured. Both IgG1 and IgG2a levels were significantly (all $P$ values $<0.001$ ) increased at 2,4 and 6 wpv compared with the two controls (PBS plus adjuvant and PBS alone), but vaccination with $\mathrm{r} B s c$-PYP-1 induced a more clear pattern of IgG1 response (Figure 7B).

In trial II, compared with the controls, a significant IgG response was also detected in the group immunized with $\mathrm{r} B s c$-PYP-1/FCA $(P<0.001)$ (Figure 7A); however, due to the challenge timepoint being earlier than that in trial I, the level of $\mathrm{rBsc}$-PYP-1-specific IgG in immunized mice seemed to decline after 4 wpv to lower levels than those in trial I until the end of the study, with the exception of the 3 and 7 wpc timepoints. Similar antibody changes were also observed in the IgG1 and IgG2a subclasses (see Figure 7B). No significant differences in the trend or level of antigen-specific IgE and IgM responses were found in trial II when compared with those in trial I (data not shown). Additionally, as seen in Figure 7, the IgG, IgG1 or IgG2a titers in the two controls of these two trials, appeared to slightly increase after mice were challenged with $B$. schreoderi infective embryonated eggs, although statistically significant differences were still observed between them and the vaccination group. In contrast, no significant responses were noted prior to exposure to this parasite.

\section{Cytokine responses in stimulated splenocyte culture supernatants}

Cytokine secretion in rBsc-PYP-1-stimulated splenocyte culture supernatants was quantified by ELISA in trial I and further confirmed in trial II. In trial I, in vitro-stimulated splenic $\mathrm{T}$ cells from mice vaccinated with $\mathrm{rBsc}$ PYP-1/FCA secreted a significantly higher level of IL-10 $(P<0.001)$ and a significantly increased level of IL-4 $(P<0.01)$ (Th2-type cytokines), compared with the levels in stimulated $\mathrm{T}$ cells from two non-vaccinated controls (FCA mixed with PBS and PBS alone) (Figure 8). However, stimulated $\mathrm{T}$ cells from immunized mice released slight but nonsignificant increases of both IFN- $\gamma$ and IL-2 (Th1-type cytokines) levels $(P>0.05)$ compared with those from T cells of non-vaccinated controls (Figure 8). Together, these results indicate that the rBsc-PYP-1 antigen induced a predominantly Th2-type immune response in experimentally vaccinated mice. Considering the inherent variability of measuring cytokine responses ex vivo, this assay was repeated in a second trial under the same experimental conditions. Encouragingly, a similar cytokine secretion profile was detected in trial II and further validated the conclusion proposed above. In comparing these results from trials I and II, no statistically significant differences were seen (Figure 8).

\section{Discussion}

B. schroederi is increasingly recognized as an important cause of mortality in giant pandas $[4,7,8,14]$, but a preventative vaccine is currently lacking. As PPases are essential for growth and viability in various organisms including parasites $[21,22]$, they are attractive targets for vaccine development against parasitic infections. Specifically, Islam et al. showed in an A. suum mouse infection model that vaccination with the $E$. coli-expressed recombinant antigen rAsPPase could confer significant hostprotective immunity against parasite challenge [23]. Unfortunately, no information on PPases of $B$. schroederi has been reported thus far. In the present study, a new B. schroederi PPase designated as Bsc-PYP-1 was identified, cloned and expressed, and its potential as a vaccine for the control of $B$. schroederi infection was evaluated using a mouse challenge model.

Extensive protein database searches revealed that the deduced amino acid sequence of Bsc-PYP-1 is highly similar to the A. suum PPase protein AdR44 and moderately similar to PPase homologues from other nematode species, while failing to share comparable levels of similarity (all values $<20 \%$ ) with any available PPase proteins from mammals, including the giant panda, the specific host of B. schroederi (Figure 1A). These observations along with the presence of the PPase signature domain and 13 evolutionarily well-conserved residues, suggest that Bsc-PYP-1 is a novel nematode-specific PPase with the likely potential to be developed as a vaccine candidate against disease caused by B. schroederi in the giant panda. Since parasite-specific molecular antigens with no or low similarity to host proteins are desirable as vaccines for parasitic infections because of antibodies induced against them without cross-reaction with host proteins [46-48]. Similar parasite-specific antigens have been reported in other nematodes, such as human filarial B. malayi (ALT1, 2 antigens) [49] and swine roundworm A. suum (14 kDa and $16 \mathrm{kDa}$ antigens) [44,50]. By immunoblot analysis, $\mathrm{r} B s c$-PYP-1 shows good antigenicity and immunogenicity, which are properties of an ideal vaccine candidate. Therefore, we further examined whether $\mathrm{rBsc}$-PYP-1 could provide protection in a $B$. schroederi challenge mouse model. Encouragingly, our data from two separate trials consistently show that 


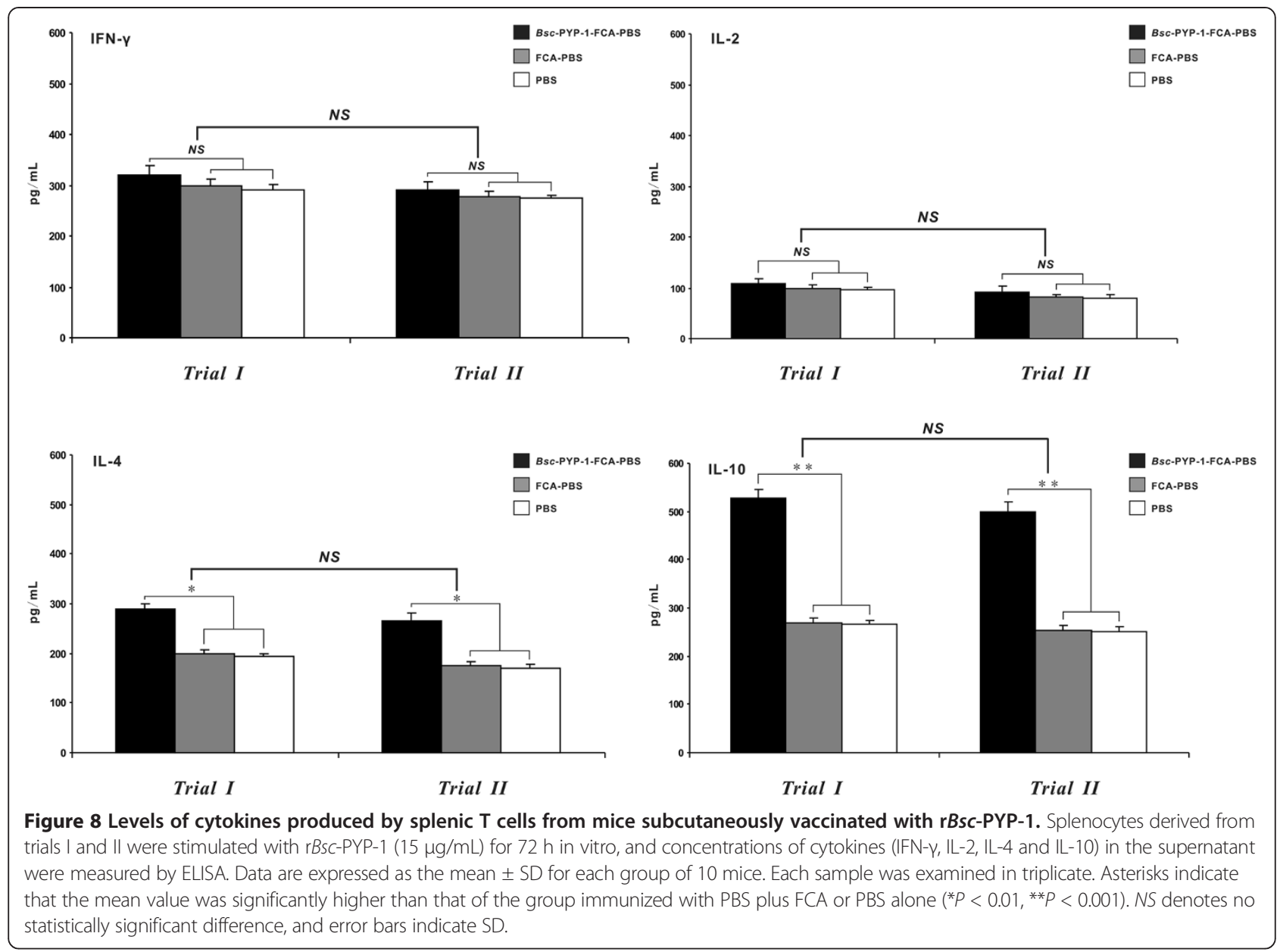

immunization of $\mathrm{BALB} / \mathrm{c}$ mice (one primary immunization and two boosters at 2-week intervals) with rBsc-PYP-1 coupled with FCA resulted in protection against migrating $B$. schreoderi larvae in the liver and lung. For both trials I and II, the protection was represented by significant reductions in the number of recovered $B$. schreoderi liver-stage L3 in livers and larvae from lungs after challenge, compared with control mice (Figure 5 and data not shown). Additionally, histopathological damage as revealed by the typical verminous interstitial hepatitis or verminous pneumonia [32] present on the liver and lung of $\mathrm{rBsc}$-PYP-1vaccinated mice was also significantly reduced following challenge (not shown). Thus, our study indicates that subcutaneous vaccination of mice with $\mathrm{rBsc}$-PYP$1 / F C A$ efficiently induced protective immunity against B. schroederi larval infection.

The immunoprotective effects of $\mathrm{r} B s c$-PYP-1 were further confirmed by the high level of protection from death after parasitic challenge in trial I, with an RPS rate of up to $80 \%$ in the vaccinated group monitored until 80 dpc, compared with controls (Figure 6). It is possible that vaccination could alter larval migration from the liver to lung to other sites that are less lethal than normal (e.g., diversion from the brain) or inhibit larval molting and development in a manner that is less pathogenic. However, such a high RPS observed in the vaccinated group appeared to be closely associated with specific $\mathrm{rBsc}$-PYP-1 humoral and cellular immune responses. We found that mice immunized with $\mathrm{rBsc}$-PYP1 produced high antigen-specific IgG antibody titers during the experiment. The anti-rBsc-PYP-1 IgG1 levels increased to a greater extent than that of anti-rBsc-PYP1 IgG2a, suggesting that $\mathrm{r} B s c$-PYP-1/FCA vaccination induced a Th2-type immune response. Interestingly, no antigen-specific IgE response was detected in these mice, suggesting that $\mathrm{r} B s c$-PYP-1 may be a non-allergenic molecule, and immune responses to $\mathrm{rBsc}$-PYP-1 were not mediated by hypersensitivity reactions. IgM responses were also detected at only a background level until 1 wpc (data not shown). Similar conclusions were drawn in the repeat experiment (trial II) with different challenge timepoints. Previous studies have associated parasitespecific IgG and IgE responses with protective immunity 
to human ascariasis [51,52]. Similar antibody responses have also been reported in experimental pigs or mice immunized either by repeated inoculation of A. suum embryonated eggs or by parasite crude or recombinant antigens $[50,53]$. However, to date, the functional significance of these two antibody types in protective responses to parasite infection remains to be defined. It is reasonable to assume that protection, as determined by RPS, in the $B$. schroederi infection mouse model may be associated with high levels of total IgG and both IgG subclasses (IgG1 and IgG2a). Further investigation using pooled sera from $r B s c-$ PYP-1/FCA immunized mice for passive immunization may be used to examine the potential of these antibodies in blocking B. schroederi larval migration and consequently death in experimentally infected mice. In addition, the antibody titers of total IgG, IgG1 and IgG2a detected in the controls (trials I and II) increased slightly after challenge. This pattern of antibody responses, which is a common phenomenon in vaccine studies of Baylisascaris spp. (e.g., Baylisascaris transfuga) where the kinetics of tested antibodies (including IgG and IgG subclasses) in nonvaccinated animals characteristically rise after challenge (H.M. Nie and Y. Fu, personal observations and unpublished data), is putatively attributed to low quantities of the native antigen present in larvae and the tissue localization of the endogenous protein in these parasites.

Analysis of antibody responses indicates that $\mathrm{rBsc}$ PYP-1 plus FCA induced a remarkable Th2-type protective immunity in vaccinated mice. This conclusion was supported by subsequent cytokine analyses from two independent trials, in which the in vitro-stimulated splenic $\mathrm{T}$ cells from $\mathrm{r} B s c$-PYP-1-immunized mice secreted a significantly high level of IL-10 and a significantly increased level of IL-4 (both Th2-type cytokines), while producing only low levels of the Th1-type cytokines IFN- $\gamma$ and IL-2. Since IL-10 is well-known to play an antagonist role in the production of IFN- $\gamma$ and IL-2, it was likely that a high production of $\mathrm{IL}-10$ by $\mathrm{CD}^{+} \mathrm{T}$ cells suppressed the synthesis of these cytokines by Th1 cells and $\mathrm{CD}^{+}$lymphocytes in mice subcutaneously immunized with $\mathrm{rBsc}$-PYP-1/FCA [54,55]. Additionally, an elevated level of IL-4 $(P<0.01)$ in immunized mice apparently did not contribute to IgE production in our study. By contrast, previous investigations in mice exploring regulatory and biological functions of parasiteinduced cytokine responses indicated IL-4 as a potent cytokine with the ability to drive IgE production [56]. Thus, further analysis using IL-4-deficient mice is needed to clarify this phenomenon. Islam et al. showed that mice immunized with rAs24 coupled with FCA elicited production of a dominant Th2-type cytokine IL-10, together with IFN- $\gamma$ but not IL-2, and conferred protection against challenge as demonstrated by a $58 \%$ reduction in recovery and stunted development of $A$. suum lung-stage larvae at 7 dpc [57]. Hence, we hypothesize that IL-10 may play an important role in cellular immune responses induced by $\mathrm{rBsc}$-PYP-1/FCA and even may directly contribute to the protective immunity against $B$. schroederi infection in mice. Interestingly, this hypothesis is supported by a previous finding that IL-10 is crucial for resistance and survival of mice infected with Trichuris muris [58].

Currently, effector mechanisms that induce stunted development and prevent migration of $B$. schroederi larvae after exiting through the host's gut wall remain poorly understood. Encouragingly, several studies have verified that specific IgG antibodies from mice immunized with $A$. suum recombinant antigens (rAs24 or rAsPPase) can penetrate the cuticle of $A$. suum larvae during the course of their liver-lung migration and neutralize the corresponding endogenous proteins, thereby interfering with larval migration and/or growth and development [23,57]. Additional studies have shown that the nematode cuticle is a dynamic structure with important absorptive, secretory and enzymatic functions and not merely an inert covering as was once believed $[23,59]$. These observations together with our analysis of IgG responses (Figure 7A) suggest a conspicuous reduction of $\mathrm{rBsc}$-PYP-1-specific antibody after challenge with infective embryonated eggs, probably due to similar antibody neutralization of endogenous Bsc-PYP-1 proteins from migrating B. schroederi larvae. This assumption may be tested in future in vitro inhibition or toxicity studies of $B$. schroederi larvae using anti-rBsc-PYP-1 IgG. It should be noted that the protective responses to $\mathrm{r} B s c$-PYP-1 against intestinal adult stage worms were not examined in the present study. Indeed, immune responses against tissue-dwelling or tissuemigratory helminths can be different from those against gastrointestinal parasites [60].

Nematode parasites (including B. schroederi) are multicellular eukaryotes with complex life cycle stages, and the adults possess a full complement of immune evasion strategies [61]. Therefore, finding a specific immune mechanism that would effectively decrease worm burden is extremely difficult, and protection often involves both humoral and cell-mediated responses [62,63]. In the present study, immunization with $\mathrm{r} B s c$-PYP-1/FCA induced strong Th2-biased humoral and cellular immune responses and conferred protection against $B$. schroederi challenge, as characterized by significant $(P<0.001)$ levels of antibodies (e.g., IgG and IgG subclasses, IgG1 > IgG2a) and IL-10 cytokine (Figure 7 and Figure 8), as well as significant $(P<0.001)$ reductions $(69.2 \%$ and $71.15 \%$ ) in larval recovery (Figure 5) compared with both controls. These results, to a certain extent, implied the potential importance of a rBsc-PYP-1-induced Th2mediated immune mechanism in fighting $B$. schroederi infection. This current study coupled with the existing evidence from other gastrointestinal nematode infections 
in various experimental animal models [27-30], confirmed once again that a nematode-specific Th2 response is essential for host parasite clearance during infection. Certainly, more studies should be performed to reinforce or renew this conclusion. Furthermore, the percentage of reduction in larval load caused by BscPYP-1 in our study (69.2-71.15\%) was comparable or slightly higher than those previously reported with $B$. schroederi-specific antigens: Bs-Ag1 (69.2\%) [26], BsAg2 (63.66\%) [12] and Bs-Ag3 (62.91\%) [13]. To a certain extent, these results suggest that under the same route and dose in the same adjuvant, Bsc-PYP-1 may more effectively confer protective immunity against migrating larvae of $B$. schroederi in the host, the giant panda, compared to the three other proteins. Future clinical vaccine examinations simultaneously testing these four B. schroederi-derived antigens in pandas would confirm this assertion. Of course, the vaccination protocol for $\mathrm{rBs}$-PYP-1, as a new candidate antigen screened from the parasite B. schroederi, will require further optimization by evaluating different adjuvants and administration routes in order to enhance immune responses.

In summary, we identified and characterized a new B. schroederi protective antigen commonly expressed in all life-cycle stages of this parasite as a PPase (BsCPYP-1). Our results demonstrate that subcutaneous vaccination of mice with $E$. coli-expressed rBsc-PYP-1, coupled with FCA, resulted in a remarkable Th2-type protective immunity against $B$. schroederi challenge, and the protection was evident by the significant reduction of parasitic load and the high survival rate in vaccinated mice. These findings provide insight into rBsc-PYP-1-induced mechanisms that trigger Th2-type immune responses, which may be important in hostprotective immunity against $B$. schroederi larvae infection, and they should contribute to further development of Bsc-PYP-1 as a candidate vaccine against ascariasis, including baylisascariasis.

\section{Abbreviations \\ PPases: Inorganic pyrophosphatases; Bsc-PYP-1: B. schroederi PPase; rBsc- PYP-1: Recombinant Bsc-PYP-1; FCA: Freund's complete adjuvant: PBS: Phosphate-buffered saline; PBS-T: PBS containing 0.05\% Tween 20; TBS: Tris-buffered saline; TBST: TBS-Tween 20; IPTG: Isopropyl- $\beta$-D- thiogalactopyranoside; SDS-PAGE: Sodium dodecyl sulfate-polyacrylamide gel electrophoesis; ELISA: Enzyme-linked immunosorbent assay; BSA: Bovine serum albumin; OPD: O-phenylenediamine dihydrochloride; OD: Optical density; HBSS: Hanks balance salt solution; SD: Standard deviations; L2-L3: 2nd and 3rd-stage larvae; SPF: Specific pathogen free; ORF: Open reading frame; Ig $G_{1}:$ Immunoglobulin $E_{;}$IgG 1 : Immunoglobulin G class 1; IgG2a: Immunoglobulin G class 2a; IgM: Immunoglobulin M; IgE: Immunoglobulin E; IL-2: IL-4, IL-10, interleukin 2, 4, and 5, respectively; IFN- $\gamma$ : Interferon $\gamma_{;}$Th1 and Th2: T cell helper type 1 and 2; RPS: Relative percent of survival; ANOVA: Analysis of variance; LSD: Least significant difference; NS: Not significant.}

\section{Competing interests}

The authors declare that they have no competing interests.

\section{Authors' contributions}

YX and SJC participated in the design of the study, performed the experiments, collected and analyzed data, and completed manuscript preparation. YBY ZHZ and $\mathrm{HY}$ carried out animal immunoprotective trials and immunoassays. $X B G, X N$ and $X Z$ participated in the recombinant vaccine preparation and assisted in the migrating larvae collection from experimental animals. DSL, CDW, SXW and XRP contributed with the coordination of immunoprotective trials and participated in the design, coordination and analyses of the study. GYY conceived of the study, and participated in its design and coordination and helped to interpret the results and edited the manuscript. All authors read and approved the final manuscript.

\section{Acknowledgments}

This work was supported by grants from the Science \& Technology Ministry, China (No.200910188) and Chengdu Giant Panda Breeding Research Foundation (No.CPF-2012-13). The authors thank DYY, GYH, YF and HMN from Sichuan Agricultural University of China, and MWL from Guangdong Ocean University of China, for their excellent technical assistance and discussion.

\section{Author details}

${ }^{1}$ Department of Parasitology, College of Veterinary Medicine, Sichuan Agricultural University, Ya'an 625014, China. ${ }^{2}$ Sichuan Entry-Exit Inspection and Quarantine Bureau, Chengdu 610041, China. ${ }^{3}$ The Sichuan Key Laboratory for Conservation Biology on Endangered Wildlife-Developing toward a State Key Laboratory for China, Chengdu Research Base of Giant Panda Breeding, Chengdu, Sichuan 610081, China. ${ }^{4}$ China Conservation and Research Center for Giant Panda, Wolong 623006, China. ${ }^{5}$ Department of Chemistry, College of Life and Basic Science, Sichuan Agricultural University, Ya'an 625014, China.

Received: 18 November 2012 Accepted: 26 September 2013

Published: 03 October 2013

\section{References}

1. Gavin PJ, Kazacos KR, Shulman ST: Baylisascariasis. Clin Microbiol Rev 2005 18:703-718.

2. Okulewicz A, Buńkowska K: Baylisascariasis-a new dangerous zoonosis. Wiad Parazytol 2009, 55:329-334 (in Polish).

3. Bauer C: Baylisascariosis-infections of animals and humans with 'unusual' roundworms. Vet Parasitol 2013, 193:404-412.

4. Zhang L, Yang X, Wu H, Gu X, Hu Y, Wei F: The parasites of giant pandas: individual-based measurement in wild animals. J Wildl Dis 2011, 47:164-171.

5. Schaul JC: Baylisascaris transfuga in captive and free-ranging populations of bears (Family: Ursidae). Columbus: Ohio State University: PhD thesis; 2006.

6. Xie Y, Zhang Z, Niu L, Wang Q, Wang C, Lan J, Deng J, Fu Y, Nie H, Yan N, Yang D, Hao G, Gu X, Wang S, Peng X, Yang G: The mitochondrial genome of Baylisascaris procyonis. PLOS One 2011, 6:e27066.

7. Xie Y, Zhang Z, Wang C, Lan J, Li Y, Chen Z, Fu Y, Nie H, Yan N, Gu X, Wang S, Peng $X$, Yang G: Complete mitochondrial genomes of Baylisascaris schroederi, Baylisascaris ailuri and Baylisascaris transfuga from giant panda, red panda and polar bear. Gene 2011, 482:59-67.

8. Zhang JS, Daszak P, Huang HL, Yang GY, Kilpatrick AM, Zhang S: Parasite threat to panda conservation. Ecohealth 2008, 5:6-9.

9. Loeffler K, Montali RJ, Rideout BA: Diseases and pathology of giant pandas. In Giant Pandas: Biology, Veterinary Medicine and Management. Edited by Wildt DE, Zhang AJ, Zhang HM, Janssen DL, Ellis S. Cambridge: Cambridge University Press; 2006:377-409.

10. Zhang ZH, Wei FW: Giant Panda Ex-situ Conservation Theory and Practice. Beijing: Science Press; 2006.

11. Zhang W, Yie S, Yue B, Zhou J, An R, Yang J, Chen W, Wang C, Zhang L, Shen F, Yang G, Hou R, Zhang Z: Determination of Baylisascaris schroederi infection in wild giant pandas by an accurate and sensitive PCR/CE-SSCP method. PLoS One 2012, 7:e41995.

12. He G, Wang T, Yang G, Fei Y, Zhang Z, Wang C, Yang Z, Lan J, Luo L, Liu L: Sequence analysis of Bs-Ag2 gene from Baylisascaris schroederi of giant panda and evaluation of the efficacy of a recombinant Bs-Ag2 antigen in mice. Vaccine 2009, 27:3007-3011.

13. Wang T, He G, Yang G, Fei Y, Zhang Z, Wang C, Yang Z, Lan J, Luo L, Liu L: Cloning, expression and evaluation of the efficacy of a recombinant Baylisascaris schroederi Bs-Ag3 antigen in mice. Vaccine 2008, 26:6919-6924. 
14. Lin Q, Li HM, Gao M, Wang XY, Ren WX, Cong MM, Tan XC, Chen CX, Yu SK, Zhao GH: Characterization of Baylisascaris schroederi from Qinling subspecies of giant panda in China by the first internal transcribed spacer (ITS-1) of nuclear ribosomal DNA. Parasitol Res 2012, 110:1297-1303.

15. Heinonen JK: Biological Role of Inorganic Pyrophosphate. Norwell: Kluwer Academic Publishers; 2001.

16. Chen J, Brevet A, Fromant M, Leveque F, Schmitter J, Blanquet S, Plateau P: Pyrophosphatase is essential for growth of Escherichia coli. J Bacteriol 1990, 172:5686-5689.

17. Lundin M, Baltscheffsky $H$, Ronne $H$ : Yeast PPA2 gene encodes a mitochondrial inorganic pyrophosphatase that is essential for mitochondrial function. J Biol Chem 1991, 266:12168-12172.

18. Ko KM, Lee W, Yu JR, Ahnn J: PYP-1, inorganic pyrophosphatase, is required for larval development and intestinal function in $C$. elegans. FEBS Lett 2007, 581:5445-5453.

19. Islam MK, Miyoshi T, Kasuga-Aoki H, Isobe T, Arakawa T, Matsumoto Y, Tsuj $\mathrm{N}$ : Inorganic pyrophosphatase in the roundworm Ascaris and its role in the development and molting process of the larval stage parasites. Eur J Biochem 2003, 270:2814-2826.

20. Jelitto T, Sonnewald U, Willmitzer L, Hajirezeai M, Stitt M: Inorganic pyrophosphate content and metabolites in potato and tobacco plants expressing E. coli pyrophosphatase in their cytosol. Planta 1992, 188:238-244.

21. McIntosh MT, Drozdowicz YM, Laroiya K, Rea PA, Vaidya AB: Two classes of plant-like vacuolar-type $\mathrm{H}+-$ pyrophosphatases in malaria parasites. $\mathrm{Mol}$ Biochem Parasitol 2001, 114:183-195.

22. Hewitson JP, Harcus YM, Curwen RS, Dowle AA, Atmadja AK, Ashton PD, Wilson A, Maizels RM: The secretome of the filarial parasite, Brugia malayi: proteomic profile of adult excretory-ecretory products. Mol Biochem Parasitol 2008, 160:8-21.

23. Islam MK, Miyoshi T, Yamada M, Tsuji N: Pyrophosphatase of the roundworm Ascaris suum plays an essential role in the worm's molting and development. Infect Immun 2005, 73:1995-2004.

24. Islam MK, Miyoshi T, Yamada M, Alim MA, Huang X, Motobu M, Tsuji N: Effect of piperazine (diethylenediamine) on the moulting, proteome expression and pyrophosphatase activity of Ascaris suum lung-stage larvae. Acta Trop 2006, 99:208-217.

25. Köhler P, Marhöfer RJ: Selective Drug Targets in Parasites. In Antiparasitic and Antibacterial Drug Discovery: From Molecular Targets to Drug Candidates. Edited by Selzer PM. Weinheim: Wiley-VCH Verlag GmbH \& Co. KGaA; 2009:75-98.

26. He G, Chen S, Wang T, Yan Y, Zhang Z, Li D, Yu H, Xie Y, Wang C, Gu X, Wang S, Peng $X$, Yang G: Sequence analysis of the Bs-Ag1 gene of Baylisascaris schroederi from the giant panda and an evaluation of the efficacy of a recombinant Baylisascaris schroederi Bs-Ag1 antigen in mice. DNA Cell Biol 2012, 31:1174-1181.

27. Geiger SM, Massara CL, Bethony J, Soboslay PT, Carvalho OS, Corrêa-Oliveira R: Cellular responses and cytokine profiles in Ascaris lumbricoides and Trichuris trichiura infected patients. Parasite Immunol 2002, 24:499-509.

28. Harris NL: Advances in helminth immunology: optimism for future vaccine design? Trends Parasitol 2011, 27:288-293.

29. Patel N, Kreider T, Urban JF Jr, Gause WC: Characterisation of effector mechanisms at the host: parasite interface during the immune response to tissue-dwelling intestinal nematode parasites. Int J Parasito/ 2009, 39:13-21.

30. Turner JD, Faulkner H, Kamgno J, Cormont F, Van-Snick J, Else KJ, Grencis RK, Behnke JM, Boussinesq M, Bradley JE: Th2 cytokines are associated with reduced worm burdens in a human intestinal helminth infection. $J$ Infect Dis 2003, 188:1768-1775.

31. Crompton DW: Ascaris and ascariasis. Adv Parasitol 2001, 48:285-375.

32. Li JH: Migration, distribution and development of larvae of panda ascarid, Baylisascaris schroederi, in mice. Acta Zool Sin 1990, 36:236-243.

33. The Open Reading Frame (ORF) Finder [http://www.ncbi.n/m.nih.gov/ projects/gorf/]

34. BLAST: Basic Local Alignment Search Tool [http://blast.ncbi.nlm.nih.gov/ Blast.cgi]

35. Align Sequences using ClustalW2 | EBI [http://www.ebi.ac.uk/Tools/msa/ clustalw2/]

36. Saitou N, Nei M: The neighbor-joining method: a new method for reconstructing phylogenetic trees. Mol Biol Evol 1987, 4:406-425.

37. Kumar S, Tamura K, Nei M: MEGA3: integrated software for molecular evolutionary genetics analysis and sequence alignment. Brief Bioinform 2004, 5:150-163.

38. ExPASy - ProtParam tool [http://www.expasy.ch/tools/protparam.html]
39. SignalP 3.0 Server [http://www.cbs.dtu.dk/services/SignalP/]

40. Bell BA, Wood JF, Bansal R, Ragab H, Cargo J, Washington MA, Wood CL, Ware LA, Ockenhouse CF, Yadava A: Process development for the production of an E. coli produced clinical grade recombinant malaria vaccine for Plasmodium vivax. Vaccine 2009, 27:1448-1453.

41. Slotved HC, Roepstorff A, Barnes EH, Eriksen L, Nansen P: Comparison of two methods for recovering migrating Ascaris suum larvae from the liver and lungs of pigs. J Parasitol 1996, 82:612-615.

42. Sun Y, Liu CS, Sun L: Comparative study of the immune effect of an Edwardsiella tarda antigen in two forms: subunit vaccine vs DNA vaccine. Vaccine 2011, 29:2051-2057.

43. Pérez-Martín E, Gómez-Sebastián S, Argilaguet JM, Sibila M, Fort M, Nofrarías M, Kurtz S, Escribano JM, Segalés J, Rodríguez F: Immunity conferred by an experimental vaccine based on the recombinant PCV2 Cap protein expressed in Trichoplusia ni-larvae. Vaccine 2010, 28:2340-2349.

44. Tsuji N, Suzuki K, Kasuga-Aoki H, Matsumoto Y, Arakawa T, Ishiwata K, Isobe $\mathrm{T}$ : Intranasal immunization with recombinant Ascaris suum 14kilodalton antigen coupled with cholera toxin $B$ subunit induces protective immunity to $A$. suum infection in mice. Infect Immun 2001 69:7285-7292.

45. Nouir NB, Eschbach ML, Piédavent M, Osterloh A, Kingsley MT, Erttmann K, Brattig N, Liebau E, Fleischer B, Breloer M: Vaccination with Strongyloides ratti heat shock protein 60 increases susceptibility to challenge infection by induction of Th1 response. Vaccine 2012, 30:862-871.

46. Abraham D, Leon O, Leon S, Lustigman S: Development of a recombinant antigen vaccine against infection with the filarial worm Onchocerca volvulus. Infect Immun 2001, 69:262-270.

47. Islam MK, Miyoshi T, Yokomizo Y, Tsuji N: Molecular cloning and partial characterization of a nematode-specific 24 kDa protein from Ascaris suum. Parasitology 2005, 130:131-139.

48. Tsuji N, Kasuga-Aoki H, Isobe T, Arakawa T, Matsumoto Y: Cloning and characterisation of a highly immunoreactive $37 \mathrm{kDa}$ antigen with multiimmunoglobulin domains from the swine roundworm Ascaris suum. Int J Parasitol 2002, 32:1739-1746.

49. Gregory WF, Atmadja AK, Allen JE, Maizels RM: The abundant larval transcript-1 and-2 genes of Brugia malayi encode stage-specific candidate vaccine antigens for filariasis. Infect Immun 2000, 68:4174-4179.

50. Tsuji N, Suzuki K, Kasuga-Aoki H, Isobe T, Arakawa T, Matsumoto Y: Mice intranasally immunized with a recombinant 16-kilodalton antigen from roundworm Ascaris parasites are protected against larval migration of Ascaris suum. Infect Immun 2003, 71:5314-5323.

51. Cooper PJ, Chico ME, Sandoval C, Espinel I, Guevara A, Kennedy MW, Urban JF Jr, Griffin GE, Nutman TB: Human infection with Ascaris lumbricoides is associated with a polarized cytokine response. J Infect Dis 2000, 182:1207-1213.

52. McSharry C, Xia Y, Holland CV, Kennedy MW: Natural immunity to Ascaris lumbricoides associated with immunoglobulin $\mathrm{E}$ antibody to ABA-1 allergen and inflammation indicators in children. Infect Immun 1999, 67:484-489.

53. Serrano FJ, Reina D, Frontera E, Roepstorff A, Navarrete I: Resistance against migrating Ascaris suum larvae in pigs immunized with infective eggs or adult worm antigens. Parasitology 2001, 122:699-707.

54. Mowen KA, Glimcher LH: Signaling pathways in Th2 development. Immunol Rev 2004, 202:203-222.

55. Sher A, Fiorentino D, Caspar P, Pearce E, Mosmann T: Production of IL-10 by CD4+ T lymphocytes correlates with down-regulation of Th1 cytokine synthesis in helminth infection. J Immunol 1991, 147:2713-2716.

56. Finkelman FD, Pearce EJ, Urban JF Jr, Sher A: Regulation and biological function of helminth-induced cytokine responses. Immunol Today 1991, 12:A62-A66.

57. Islam MK, Miyoshi T, Tsuji N: Vaccination with recombinant Ascaris suum 24-kilodalton antigen induces a Th1/Th2-mixed type immune response and confers high levels of protection against challenged Ascaris suum lung-stage infection in BALB/c mice. Int J Parasitol 2005, 35:1023-1030.

58. Schopf LR, Hoffmann KF, Cheever AW, Urban JF Jr, Wynn TA: IL-10 is critical for host resistance and survival during gastrointestinal helminth infection. J Immunol 2002, 168:2383-2392.

59. Maizels RM, Blaxter ML, Selkirk ME: Forms and functions of nematode surfaces. Exp Parasitol 1993, 77:380-384.

60. Garside P, Kennedy MW, Wakelin D, Lawrence CE: Immunopathology of intestinal helminth infection. Parasite Immunol 2000, 22:605-612. 
61. Schmid-Hempel P: Parasite immune evasion: a momentous molecular war. Trends Ecol Evol 2008, 23:318-326.

62. Jarrett $\mathrm{EE}$, Urguhart $\mathrm{GM}$ : The immune response to nematode infections. Int Rev Trop Med 1971, 4:53-96.

63. Anthony RM, Rutitzky LI, Urban JF Jr, Stadecker MJ, Gause WC: Protective immune mechanisms in helminth infection. Nat Rev Immunol 2007, 7:975-987.

doi:10.1186/1297-9716-44-90

Cite this article as: Xie et al:: Potential of recombinant inorganic pyrophosphatase antigen as a new vaccine candidate against Baylisascaris schroederi in mice. Veterinary Research 2013 44:90.

\section{Submit your next manuscript to BioMed Central and take full advantage of:}

- Convenient online submission

- Thorough peer review

- No space constraints or color figure charges

- Immediate publication on acceptance

- Inclusion in PubMed, CAS, Scopus and Google Scholar

- Research which is freely available for redistribution 